\title{
Apexification of Traumatically Injured Teeth: A Comparison between Biodentine and Mineral Trioxide Aggregate
}

\author{
Muna Saleem Khalaf \\ Lecturer at the Department of Pedodontics \& Preventive Dentistry, Baghdad Teaching Hospital, \\ College of Dentistry, Baghdad University, Iraq
}

\begin{abstract}
The traditional approach to the treatment of traumatized immature non-vital teeth has been apexification by inducing the formation of mineralized tissue in the apical portion of incompletely formed apex. Several materials have been introduced in order to offer an apical barrier with biocompatible properties, not cytotoxic and promote induction of calcific bridge formation and periapical healing. The aim of this study is to compare the success rate of the use of MTA and biodentine in apexification and periapical healing of teeth with incomplete root formation and periapical infection. Materials and method: 20 partially developed permanent maxillary incisors that have been traumatized were treated by apexification (10 treated using MTA and 10 treated using Biodentine). Root canals treated with both types of materials were obturated with gutta-percha. The patients were recalled at 1, 3, 6, and 12 monthly intervals for clinical evaluation and radiographic evaluation of the apical barrier formation and periapical healing. Results: The follow up evaluation revealed clinical and radiographical success in all of the cases after a 12 month interval (100\%). Success involved no clinical signs or symptoms of pain or periodontal inflammation and complete healing of the periapical region with calcific barrier formation Conclusion: Both Biodentine and MTA can be used for successful apexification treatment of immature non vital permanent teeth. Biodentine represents a great improvement compared to the other calcium silicate dental materials. In contrast with MTA, the mechanical properties of Biodentine are similar to those of natural dentine.
\end{abstract}

Keywords: apexification, immature teeth, MTA, Biodentine

\section{Introduction}

Apexification is the procedure of inducing the formation of mineralized tissue in the apical portion of the incompletely developed roots of non-vital teeth[1].

Different materials have been introduced to create a physical barrier that makes obturation of the immature root canal possible. These materials includecalcium hydroxide, tricalcium phosphate, resorbable ceramic, surgicel/amalgam, freeze-dried bone or dentin. Although calcium hydroxide has been used to induce apical closure in incompletely developed roots and proved to be successful, itsprolonged application in the root canal of immature toothcauses other problems. Calcium hydroxide can reduce the fracturestrength of human dentine [2], [3].

Mineral trioxide aggregate (MTA) is a biocompatible material suitable for induction of an apical hard tissue barrier in immature, incompletely developed teeth with pulp necrosis. MTA has shown to have the ability to form a good tight seal and to induce bone formation. Another advantage is the shorter treatment time when compared with calcium hydroxide [4], [5].

MTA neither gets resorbed, nor weakens the root canal dentin, and also has the advantage of setting in the wet environment. Compaction of obturation material is achievable when MTA is used to form an apical barrier since on setting it provides a sound and hard apical barrier[6].

Biodentine has been introduced by Septodont. It is similar to MTA in its basic composition of tri-calcium silicate and dicalcium with calcium chloride added as setting
accelerators.Calcium chloride not only results in fast setting, but also improves the handling properties and strength. Previous studies have shown that Biodentine's consistency is better suited to the clinical use, does not require a two-step obturation, ensures a better handling and safety and as the setting is faster, when compared to MTA, there is a lower risk of bacterial contamination [7]

The aim of this study is to compare the success rate of the use of MTA and biodentine in apexification and periapical healing of teeth with incomplete root formation and periapical infection.

\section{Materials and Method}

The sample included in this study was obtained from the children attending the teaching hospital of the College of Dentistry, Baghdad University. The collection of the sample, treatment and follow-up started in October 2015 and ended in May 2017(the teeth weremonitoredfor up to one year).32partially developed permanent maxillary incisors[8]that have been traumatized weretreated (11 treated using MTA and 21 treated using Biodentine).The number of the treated teeth that were examined throughout the follow-up period was 20 teeth (10 treated using MTA and 10 treated using Biodentine).

Written consents for treatment were obtained prior to the clinical procedures after the details of the treatment procedure were explained to the child's parents or guardians. They were also told that the treatment was part of a study that required their cooperation to attend at recalls for follow-up. Patients that did not return for follow up on call were excluded from the study. An information record for

Volume 6 Issue 12, December 2017 


\section{International Journal of Science and Research (IJSR) \\ ISSN (Online): 2319-7064}

Index Copernicus Value (2016): 79.57 | Impact Factor (2015): 6.391

each child was filled with information concerning the general health of the child in addition to the chief complain and reason for attending the hospital.History of the traumatized tooth/teethand clinical oral findings were also recorded. The amount of coronal fracture (according to Ellis classification of tooth fracture $\left.{ }^{(8)}\right)$, discoloration, mobility, tenderness to percussion and pulp vitality were recorded also. A diagnostic periapical radiograph (Dentafilm Ergonom-x, 'D' class film, Italy) was taken to evaluate the condition of the root; if any root resorption was identified or root fractures and if there was periapical pathology associated with the root. Teeth selected for this study were all subjected to coronal fracture, with or without exposure of the pulp, and were not treated at the time of injury or were treated but the treatment failed. The outcome was pulpal necrosis.

Local anesthesia was administered when treating tender teeth. Isolation of the traumatized tooth was then established and proper unrestricted access was done to ensure complete access to the canal walls in order to acquire adequate debridement. Root canal length was estimated 2-3 mm shorter than the apex from the dental radiograph.After complete removal of the necrotic pulp tissue, irrigation of the canal was performed using copious amounts of $5 \%$ sodium hypochlorite. Instrumentation of the canal was carriedout by the use of k-files (DENTSPLY, MAILEFER, Swiss) to debride and shape the root canal walls.Irrigation was repeated throughout the procedure of instrumentation ${ }^{(8)}$.The canal was then dried with premeasured absorbent paper pointsto the working length followed by application of a non-setting calcium hydroxide dressing (Metapex, Meta Biomed Co. Ltd., Chungcheongbuk-do, Korea)to the estimated working lengthand the tooth was closed with a temporary filling.After a weekthe tooth was re-openedand the dressing was removed mechanically by the use of reamers and washed out by irrigating the canal with copious amounts of sterile normal saline. After that drying the canal with paper points was done and at this time apexification was carried out using the following materials:

\subsection{Mineral Trioxide Aggregate apexification:}

MTA(PD MTA White, Produits Dentaires SA, Switzerland) was handled according to the manufacturer's instructions. The powder was mixed with distilled water in a ratio $3: 1$ for about 30 seconds until it became homogenous ${ }^{(9,}$ ${ }^{10)}$.Then it was immediately carried into the root canal orifice by the use of an amalgam carrier and into the canal to the apical region by the use of a finger plugger (DENTSPLY, MAILEFER, Swiss)[9].The working length of the finger plugger was adjusted 3-4 $\mathrm{mm}$ shorter than the estimated working length so that the apical plug formed was $4-5 \mathrm{~mm}$. The plug was checked radiographically. If creation of an ideal plug failed from the first attempt, it was rinsed with sterile saline with mechanical removing by reamers and the procedure was repeated.A moistened cotton pellet was placed over the canal orifice to allow complete setting of the material and the access cavity was sealed with glass ionomer restorative material as a temporary filling (Ionofil Combipack, Germany).The obturation of the remaining root canal space was done with gutta-perchaat a second visit which was after 2 to 7 days.

\subsection{Biodentine Apexification}

Biodentine (septodont, France) was handled according to the manufacturer's instructions also. It is presented as pre-dosed capsules containing the powder in addition to a single container of liquid for each capsule. The capsule was opened, after gently loosening the powder and five drops of liquid was added. The capsule was reclosed and mixing was carried out by an amalgumatormixing device (Silamat, Vivadent) for 30 seconds. The capsule was opened and the material was delivered to the root canal orifice and the apical region as described with MTA apexification. The thickness of the plug and correct positioning was checked radiographically. As with MTA, if creation of an ideal plug failed from the first attempt, it was rinsed with sterile saline with mechanical removing by reamers and the procedure was repeated.A dry cotton pellet was applied in the coronal portion of the orifice and the material was allowed to set. This requires 12 minutes but to assure the set the plug was left for half an hour [10].

Root canals treated with both types of materials were obturatedwith gutta-percha (META BIOMED CO. LDT, Korea) and sealer (Endofill, PD, Switzerland) by lateral compaction technique and by the use of finger spreader (DENSPLY, MAILEFER, Swiss) $)^{(10,14)}$. Periapical radiographs were taken after applying the MTA plug and the Biodentine plug and after obturating the root canal to be sure a proper seal was obtained. The patients were recalled at 3 , 6, and 12 monthly intervals for clinical evaluation and radiographic evaluation of the apical barrier formation and periapical healing according to the criteria presented by El Meligy and Avery [11]:

1) Clinical evaluation: the presence of anysigns such as swelling, pain,tendernesstopercussionorpalpation and pathological mobility wasdefinitely indicative ofclinical failure.

2) Radiographicalevaluation: The radiographs were examined carefully and compared with thepreoperative radiographs.Observation of any partial loss of the lamina dura,widening of the periodontal ligament, any sign ofpathological external or internal root resorption as well as periapical or inter-radicular radiolucencywas considered as radiographic failure.

Final restoration of the traumatized tooth was done at the end of the follow up period to restore esthetic and permanently seal the access opening by the use of light cured composite filling (Tetric N Ceram, IvoclarVivadent, Liechtenstein)(observe figures 2, 3).

The examination of the teeth treated including clinical and radiographic examination, throughout the study period, was carried out by the author. Description of the data was in numbers and percentage values.

\section{Results}

Table 1 describes the sample which involves the total number of teeth that were treated by apexification using either MTA or Biodentine (32). The number of teeth that were excluded from the study was 12 (one treated with MTA 


\section{International Journal of Science and Research (IJSR) \\ ISSN (Online): 2319-7064}

Index Copernicus Value (2016): 79.57 | Impact Factor (2015): 6.391

and 11 treated with Biodentine). The reason for their exclusion was that patients failed to return for recall visits for examination. The total number of teeth that were examined for a one-year follow-up period was 20 (10 for the MTA group and 10 for the Biodentine group).

The results found from the radiographic examination are shown in Table 2. Apical radiolucency was present at the beginning of the treatment in all but one tooth for the MTA group ( $n=9)$. While in the Biodentine group all the teeth had radiolucency apically $(\mathrm{N}=10)$. At 3 months $80 \%$ of the teeth showed healing of the apical pathosis in the MTA group. While in the Biodentine group 70\% showed healing of the apical pathosis. Complete healing of the apical radiolucency was obtained in both groups at 12 months. Calcification of an apical barrier was seen in $80 \%$ of teeth for the Biodentine group and $70 \%$ for the MTA group at 3 months. In the Biodentine group all teeth showed calcification of apical barrier after 6 months. While in the MTA group apical barrier calcification for all the teeth was seen at one year. No external or internal resorption was seen in any of the cases throughout the treatment period. All cases for both groups showed radiographic success at one year recall (100\%).

Clinical examination at recall visits are revealed in Table 3. At the beginning of the study, for both groups, most of the children complained of tenderness to percussion (70\%). These symptoms disappeared after 3 months. Periodontal symptoms that included inflammation and/or sinus and abscess tract were seen in $55 \%$ of the cases and they resolved at 3 months for both groups. At 6 months clinical success was obtained (100\%).

\section{Discussion}

At the beginning of the study all but one of the teeth had an apical radiolucency associated with the apex of the root.The presence of bacteria in the root canal system not only initiatesbut also maintains periapical inflammatory lesions. Anaerobic bacteria are the bacterial micro flora in root canal infections of untreated teeth in addition to several other species [12], [13]. The goal of root canal treatment is to eliminate bacteria from the infected root canal and prevent reinfection. Cleaning, shaping and irrigating the canal with disinfectants or antiseptics greatly reduce the number of bacteria [14].

Therefore, it was decided to apply an interappointment dressing (calcium hydroxide) for 1-2 weeks. It has been shown that $\mathrm{Ca}(\mathrm{OH}) 2$ for 7 days is highly effective in killing root canal flora. This procedure tended to control the rapid multiplication of bacteria between visits [15], [16].

Apexification of immature non vital teeth is supposed to create an environment that permits deposition of cementum, bone and periodontal ligament to enable the root development to continue normally. The aim of apexification was to obtain an apical barrier to prevent the passage of toxins and bacteria into periapicaltissues from the root canal. This barrier should allowcompaction of root filling material and toprevent overextensionof the root filling materials into the periapical tissues. The apical barrier also reduce; the surface area of the root filling which is in contact with the periapical tissues in order to reduce rate at which the sealer can be dissolved which subsequently leads to leakage of tissue fluid which will provide nutrients to any bacteria present within the root canal system [17].

According to the results of this study, both MTA and Biodentine proved to be successful clinically and radiographically. No cases showed failure of treatment. The difference between the two materials was not found in the clinical and radiographic examination but may be found in laboratory examinations since these materials are different in their composition that is expressed in the physico-chemical properties including handling properties, bioactive properties and Leakage resistance and mechanical strength. MTA is capable of modifying differentiation of both fibroblast populations resulting in increase in levels of alkaline phosphatase activity, which is an indicator of bone formation. This alkalinity has given MTA the advantage of antibacterial activity and conduction of hard tissue [18], [19].Still MTA has some shortcomings including difficult handling and long setting time. MTA also has low mechanical properties caused by the aluminate components, which make the product fragile. Another factor that affects the strength of the material is water, which is essential for the hardening of the product. Excess water in the system will create some remaining porosity, but on the other hand decreasing the water content leads to reducing the possibility of a homogenous mix. In the production of Biodentine there was an addition of hydrosoluble polymer systems described as "water reducing agents" or super plasticizers, which act in maintaining the balance between low water content and consistency of the mixture. The compressive strength, elasticity modulus and microhardness of Biodentine are comparable with that of natural dentine [20].Biodentine does not require a two-step obturation as in the case of MTA. Since the setting time is quicker this reduces the riskof bacterial contamination [21].

\section{Conclusions}

Both Biodentine and MTA can be used for successful apexification treatment of immature non vital permanent teeth. Biodentine represents a great improvement compared to the other calcium silicate dental materials. In contrast with MTA, the mechanical properties of Biodentine are similar to those of natural dentine.

\section{References}

[1] Morse DR, Larnie J, Yesilsoy C. Apexification: review of the literature. Quintessence International1990; 21(7): 589-596.

[2] Andreasen JO, Farik B, Munksgaard EC. Long-term calcium hydroxide as a root canal dressing may increase risk of root fracture. Dent Traumatol2002;18(3):134 137.

[3] Kubasad GC, Ghivari SB. Apexification with apical plug of MTA-report of cases. Arch Oral Sci Res 2011.

[4] Simon S, Rilliard F, Berdal A, Machtou P. The use of mineral trioxide aggregate in one-visit apexification treatment: a prospective study. IntEndod J2007; 40(3):186-197

\section{Volume 6 Issue 12, December 2017}




\section{International Journal of Science and Research (IJSR) \\ ISSN (Online): 2319-7064 \\ Index Copernicus Value (2016): 79.57 | Impact Factor (2015): 6.391}

[5] Bakland LK, Andreasen JO. Will mineral trioxide aggregate replace calcium hydroxide in treating pulpal and periodontal healing complications subsequent to dental trauma? A review. Dent Traumatol2012; 28(1):25-32.

[6] Arcangelo DC, Amario DM. Use of MTA for orthograde obturation of nonvital teeth with open apices: Report of two cases. OralSurg Oral Med Oral Pathol Oral RadiolEndod. 2007;104: 98-101.

[7] Pawar AM, Kokate SR, Shah RA. Management of a large periapical lesion using Biodentine TM as retrograde restoration with eighteen months evident follow-up. J Conserv Dent 2013;16:573-5.

[8] Nolla CM. the development of the permanent teeth, J Dent Child1960: 254-266.

[9] Nayak G and Hasan MF Single visit apexification with Biodentine. The Korean Academy of Conservative Dentistry. RDE. 2014;39 (2):120-125.

[10] Gurudutt N, Mohammad FH. Biodentine-a novel dentinal substitute for single visit apexification. Restor Dent Endod. 2014; 39(2):120-125).

[11]El Meligy OAS, Avery DR. Comparison of Apexification with Mineral Trioxide Aggregate and Calcium Hydroxide. Pediatric Dentistry. 2006; 28 (3): 248-253.

[12] Brauner AW, Conrads G. Studies into the microbial spectrum of apical periodontitis. International Endodontic Journal1995; 28: 244-8.,

[13]Le Goff A, Bunetel L, Mouton C, Bonnaure-Mallet M. Evaluation of root canal bacteria and their susceptibility in teeth with necrotic pulp. Oral Microbiology and Immunology 1997; 12: 318-22.

[14] Ørstavik D, Kerekes K, Molven O. Effects of extensive apical reaming and calcium hydroxide dressing on bacterial infection during treatment of apical periodontitis: a pilot study. International Endodontic Journal 1991; 24: 1-7.

[15] Sjogren U, Figdor D, Spangberg L, Sundqvist G. The antimicrobial effect of calcium hydroxide as a shortterm intracanal dressing. IntEndod J 1991; 24: 119-125

[16] Chong BS, Pitt Ford TR. The role of intracanal medication in root canal treatment. International Endodontic Journal 1992; 25: 97-106.

[17] Komabayashi T, Spångberg LS. Comparative analysis of the particle size and shape of commercially available mineral trioxide aggregates and Portland cement. J Endod 2008; 34: 94-7.

[18] Apaydin ES, Shabahang S, Torabinejad M; Hard-tissue healing after application of fresh or set MTA as rootend-filling material. J Endod 2004; 30: 21-24.

[19] Keiser K, Johnson CC, Tipton DA; Cytotoxicity of mineral trioxide aggregate using human periodontal ligament fibroblasts. J Endod2000; 26: 288-291

[20] Septodont. Biodentine - Active BiosilicateTechnology,scientific file. Saint-Maur-desFossésCedex, France: R\&D Department, Septodont; 2010.

[21]Bachoo IK, Seymour D, Brunton P. Clinical case reports using a novel calcium-based cement. Br Dent J 2013; 214:61-64.RDE.

Table 1: Description of the sample included and excluded from the study

\begin{tabular}{|c|c|c|c|}
\hline $\begin{array}{c}\text { Total number of teeth } \\
\text { treated by apexification }\end{array}$ & 32 & $\begin{array}{c}\text { Teeth excluded from the } \\
\text { study due to failure to } \\
\text { return for recall visits }\end{array}$ & $\begin{array}{c}\text { Teeth included in the } \\
\text { study that attained for } \\
\text { 1 year recall visits }\end{array}$ \\
\hline Teeth treated with MTA & 11 & 1 & 10 \\
\hline $\begin{array}{c}\text { Teeth treated with } \\
\text { Biodentine }\end{array}$ & 21 & 11 & 10 \\
\hline
\end{tabular}

Table 2: Radiographic findings of treated teeth throughout the follow-up period

\begin{tabular}{|c|c|c|c|c|c|c|c|c|c|}
\hline & \multicolumn{2}{|c|}{0 months } & \multicolumn{2}{|c|}{3 months } & \multicolumn{2}{|c|}{6 months } & \multicolumn{2}{|c|}{12 months } \\
\hline & & MTA & Biodentine & $M T A$ & Biodentine & $M T A$ & Biodentine & MTA & Biodentine \\
\hline \multirow{3}{*}{ Apical radiolucency } & Radiographic findings & $N(\%)$ & $N(\%)$ & $N(\%)$ & $N(\%)$ & $N(\%)$ & $N(\%)$ & $N(\%)$ & $N(\%)$ \\
\hline & Yes & $9(90)$ & $10(100)$ & $2(20)$ & $3(30)$ & $1(10)$ & $1(10)$ & $10(100)$ & $10(100)$ \\
\hline & $\mathrm{No}$ & $1(10)$ & 0 & $8(80)$ & $7(70)$ & $9(90)$ & $9(90)$ & $10(100)$ & $10(100)$ \\
\hline \multirow{2}{*}{ Calcification of apical barrier } & Yes & 0 & 0 & $7(70)$ & $8(80)$ & $9(90)$ & $10(100)$ & $10(100)$ & $10(100)$ \\
\hline & $\mathrm{No}$ & $10(100)$ & $10(100)$ & $3(30)$ & $2(20)$ & $1(10)$ & 0 & $10(100)$ & $10(100)$ \\
\hline \multirow{2}{*}{ External or internal resorption } & Yes & 0 & 0 & 0 & 0 & 0 & 0 & 0 & 0 \\
\hline & No & 0 & 0 & 0 & 0 & 0 & 0 & 0 & 0 \\
\hline
\end{tabular}

Table 3:Clinical findings of treated teeth throughout the follow-up period

\begin{tabular}{|c|c|c|c|c|c|c|c|c|c|}
\hline \multirow{3}{*}{\multicolumn{2}{|c|}{ Clinical findings }} & \multicolumn{2}{|c|}{0 months } & \multicolumn{2}{|c|}{3 months } & \multicolumn{2}{|c|}{6 months } & \multicolumn{2}{|c|}{12 months } \\
\hline & & MTA & Biodentine & MTA & Biodentine & MTA & Biodentine & MTA & Biodentine \\
\hline & & $\mathrm{N}(\%)$ & $\mathrm{N}(\%)$ & $\mathrm{N}(\%)$ & $\mathrm{N}(\%)$ & $\mathrm{N}(\%)$ & $\mathrm{N}(\%)$ & $\mathrm{N}(\%)$ & $\mathrm{N}(\%)$ \\
\hline Pain & $40 \%$ & $4(40)$ & $4(40)$ & 0 & 0 & 0 & 0 & 0 & 0 \\
\hline Tenderness on Percussion & $70 \%$ & $6(60)$ & $8(80)$ & $1(10)$ & $1(10)$ & 0 & 0 & 0 & 0 \\
\hline Periodontal symptoms* & $55 \%$ & $3(30)$ & $8(80)$ & 0 & 0 & 0 & 0 & 0 & 0 \\
\hline Mobility & $15 \%$ & $2(20)$ & $1(10)$ & 0 & 0 & 0 & 0 & 0 & 0 \\
\hline
\end{tabular}

*periodontal inflamed surface area, abscess and sinus tract 